Article

\title{
Efficacy of Hydrophobic Coatings in Protecting Oak Wood Surfaces during Accelerated Weathering
}

\author{
Miloš Pánek *, Eliška Oberhofnerová, Aleš Zeidler and Přemysl Šedivka \\ Department of Wood Products and Wood Constructions, Faculty of Forestry and Wood Sciences, \\ Czech University of Life Sciences Prague, Prague 165 21, Czech Republic; \\ Eliska.Oberhofnerova@seznam.cz (E.O.); zeidler@fld.czu.cz (A.Z.); sedivka@rektorat.czu.cz (P.Š.) \\ * Correspondence: panekmilos@fld.czu.cz; Tel.: +420-224-383-867
}

Received: 30 August 2017; Accepted: 10 October 2017; Published: 18 October 2017

\begin{abstract}
The durability of transparent coatings applied to an oak wood exterior is relatively low due to its anatomic structure and chemical composition. Enhancement of the protection of oak wood against weathering using transparent hydrophobic coatings is presented in this study. Oak wood surfaces were modified using UV-stabilizers, hindered amine light stabilizer (HALS), and $\mathrm{ZnO}$ and $\mathrm{TiO}_{2}$ nanoparticles before the application of a commercial hydrophobic topcoat. A transparent oil-based coating was used as a control coating system. The artificial weathering test lasted 6 weeks and colour, gloss, and contact angle changes were regularly evaluated during this period. The changes in the microscopic structure were studied with confocal laser scanning microscopy. The results proved limited durability against weathering of both tested hydrophobic coatings. The formation of micro-cracks causing the leaching of degraded wood compounds and discolouration of oak wood were observed after 1 or 3 weeks of the weathering test. Until then, an oil-based coating film had protected the wood sufficiently, but after 6 weeks the wood was fully defoliated to its non-homogenous thickness, which was caused by the presence of large oak vessels, and by the effects of specific oak tannins. Using transparent hydrophobic coatings can prolong the service life of the exteriors of wood products by decreasing their moisture content. Without proper construction protection against rainwater, the hydrophobic coating itself cannot guarantee the preservation of the natural appearance of wood exteriors.
\end{abstract}

Keywords: artificial weathering; durability; hydrophobic coatings; oak wood

\section{Introduction}

Water contained in wood is a precondition allowing wood-destroying fungi and insects to prosper [1-3]. The water synergistically interacts with solar radiation and causes atmospheric degradation of the wood surface [4-6], as well as dimensional changes and crack formation [7]. Modification in the form of hydrophobization can increase the natural durability of wood against biotic and abiotic damages on its exterior [8,9]. Modifications changing the properties of wood in its entire volume, such as thermal treatment or acetylation, are a frequent treatment method $[10,11]$. For exposures without ground contact (Class 3 according to EN 350 [1]), it is possible to use hydrophobization in the form of a coating [12]. Hydrophobic coatings have the advantage of easier application and lower cost compared to thermal treatment, acetylation, or plasma treatment, and they also preserve the original appearance of the wood, thereby positively influencing human perception [13].

Nowadays, with the development of nanotechnology, new hydrophobic coatings are being developed at a rapid pace [14,15]. The impact of their application on native wood [16-18], thermally modified or chemically treated wood [19], or application as a topcoat in coating systems [20-22] was investigated. Multilayer coating systems are currently the most used variants of wood coatings against weathering, and they are the focus of attention of many scientific studies [23,24]. Based on 
the results of experimental studies, the type of coating system influences the overall service life of coatings [25] and the underlying wood [23,26]. Particularly, wood species with high extractives content are reported as problematic in the field of coating application [27]. The use of hydrophobic layers instead of traditional coating systems has the advantage of easier application (only 1 layer of hydrophobization is sufficient). However, hydrophobic coatings only prevent damage caused by water and do not protect the underlying wood against UV and visible (VIS) spectra causing decomposition of lignin and extractives [28,29], and they are associated with chemical and colour changes [30,31]. For wood stabilization, it is possible to use protective pigments which are used as parts of coatings [25], as well as nanoparticles [32-35], UV stabilizers [36], and HALS applied in the penetration protective layer [37-39]. Changes in the colour of surface layers due to the weathering process [40] and the effects of microscopic fungi [41-43] are observed on wood [44,45] and on the protective coatings [46,47] on its exterior. In addition, the exterior of modified wood (thermally modified, acetylated, etc.) quickly turns grey [47-49] due to the deposition of dirt and dust into its porous structure. This could be potentially prevented using hydrophobic self-cleaning coatings in combination with UV stabilization of the underlying wood. Although more studies have been done to investigate the possibilities of wood surface hydrophobic modification [15,50-52], their long-term efficiency during outdoor exposure should also be considered.

Oak (Quercus robur L.) is a tree species that is widespread across Central Europe and provides high quality timber [53]. In terms of natural durability (Class 2 by EN 350 [54]), it is the only widely used domestic timber which can succeed compared to imported tropical woods. This determines the oak wood to be suitable for outdoor applications that require high bio-resistance, without the need for impregnation with fungicides [55]. Nevertheless, it also quickly loses its original colour due to weathering [56], and proper surface treatment in the form of a coating system is thereby necessary in order to maintain its natural appearance. The application of coating systems is problematic due to the uneven structure and content of tannins [53], and therefore the service life of coatings is limited [57].

The aim of this study is to evaluate the efficiency and durability of two hydrophobic coatings used in combination with the modification of underlying wood using UV stabilizing treatments. Efficiency was evaluated by measuring discolouration, gloss, and contact angle changes, as well as by confocal laser scanning microscopy during an accelerated artificial weathering test.

\section{Material and Methods}

\subsection{Wood and Coatings}

Test samples with dimensions of $40 \mathrm{~mm} \times 20 \mathrm{~mm} \times 150 \mathrm{~mm}(T \times R \times L)$ and a mean density of $\rho_{0}=705 \mathrm{~kg} / \mathrm{m}^{3}$ were prepared from oak wood (Quercus robur L.) from the Czech Republic. The samples were conditioned to a moisture content of $12 \%$, sanded by sandpaper with a grit of 120 in a longitudinal direction, and they were visually sorted. Samples without any significant colour variations were used in this study in order to exclude the colour variability factor of the tested material. The cross ends of samples were sealed using silicon as protection against additional water uptake, and surface modifications and hydrophobic coatings were subsequently applied.

In order to stabilize the underlying wood with a penetrating treatment, four different modifications (in 3\% concentration in the form of water solution or dispersion) were used. These modified samples and reference control samples (without modification) were subsequently treated with two different transparent top hydrophobic coatings, which were applied in one layer in the amount of $120 \mathrm{~g} / \mathrm{m}^{2}$ using a brush according to a recommendation from a manufacturer. An oil-based coating applied in two layers with a total amount of $120 \mathrm{~g} / \mathrm{m}^{2}$ was used as a reference control coating system for mutual comparison (Table 1), as well as oak samples (REF) without any treatment. Two samples were tested for each type of coating system. The initial colour parameters (CIE 1986 [58]) are specified in Table 2. 
Table 1. Oak wood modifications and chemical composition of the applied treatments.

\begin{tabular}{|c|c|c|}
\hline Treatment Marking & Coating or Surface Modification & Chemical Composition \\
\hline A & Hydrophobic coating (commercial product) & $\begin{array}{l}1 \% \text { butanoate nano zirconium; Isopropyl alcohol } 98 \% \text {, } \\
\text { butanol } 1 \%\end{array}$ \\
\hline B & Hydrophobic coating (commercial product) & $\begin{array}{l}\text { Water-based acrylic resin with wax additives as } \\
\text { hydrophobic substances }\end{array}$ \\
\hline C & Transparent oil-based coating (commercial product) & $\begin{array}{l}\text { Natural vegetable oils, dis-aromatized white spirit, } \\
\text { 3-iodo-2-propynyl N-butylcarbamate (IPBC) as } \\
\text { fungicide, UV-stabilizers }\end{array}$ \\
\hline 1 & UV light-stabilizer (commercial product) & $\begin{array}{l}\text { 2-(2-hydroxyfenyl)-benzotriazoles with HALS; in 3\% } \\
\text { water solution }\end{array}$ \\
\hline 2 & UV light-stabilizer and $\mathrm{ZnO}$ nanoparticles & $\begin{array}{l}\text { 2-(2-hydroxyfenyl)-benzotriazoles with HALS (1) and } \\
\text { nanoparticles of } \mathrm{ZnO}(25 \mathrm{~nm}) \text { - weight ratio of UV } \\
\text { stabilizers and nanoparticles in composition } 1: 1 ; \text { in } \\
3 \% \text { water dispersion concentration }\end{array}$ \\
\hline 3 & $\begin{array}{l}\text { UV light-stabilizer and mixture of } \mathrm{ZnO}: \mathrm{TiO}_{2} \\
\text { nanoparticles (1:1 weight ratio) }\end{array}$ & $\begin{array}{l}\text { 2-(2-hydroxyfenyl)-benzotriazoles with HALS (1); } \mathrm{ZnO} \\
(25 \mathrm{~nm}) \text { and } \mathrm{TIO}_{2}(6 \mathrm{~nm}) \text { nanoparticles-weight ratio } \\
\text { of UV stabilizers and nanoparticles in composition 1:1; } \\
\text { in } 3 \% \text { water dispersion concentration }\end{array}$ \\
\hline 4 & UV light-stabilizer (commercial product) & $\begin{array}{l}\text { Synthetic resins, organic UV light stabilizers, and } \\
\text { IPBC fungicide }\end{array}$ \\
\hline REF & Native untreated oak wood & - \\
\hline
\end{tabular}

Table 2. Initial colour parameters $L^{*}, a^{*}, b^{*}$ (CIELab 1986 [58]) of the tested samples.

\begin{tabular}{ccccccccccccc}
\hline Coating & & & A & & & & & B & & C & REF \\
\hline Modification & $\mathbf{1}$ & $\mathbf{2}$ & $\mathbf{3}$ & $\mathbf{4}$ & $\mathbf{-}$ & $\mathbf{1}$ & $\mathbf{2}$ & $\mathbf{3}$ & $\mathbf{4}$ & - & - & - \\
\hline Sign & A1 & A2 & A3 & A4 & A & B1 & B2 & B3 & B4 & B & C & REF \\
\hline$L^{*}$ & 56.5 & 54.4 & 54.1 & 56.9 & 60.9 & 59.1 & 51.4 & 54.5 & 62.8 & 61.7 & 59.0 & 67.7 \\
$a^{*}$ & 9.3 & 10.2 & 10.8 & 9.3 & 7.4 & 7.7 & 9.5 & 8.5 & 7.8 & 9.1 & 10.8 & 6.8 \\
$b^{*}$ & 24.9 & 22.4 & 27.4 & 24.7 & 22.8 & 21.6 & 21.7 & 23.3 & 21.5 & 25.2 & 26.6 & 19.7 \\
\hline
\end{tabular}

Note: For example, sign A1 means that the oak wood surface was modified by 2-(2-hydroxyfenyl)-benzotriazoles with HALS (1), and then a top layer of hydrophobic coating (A) was applied (See Table 1).

\subsection{Artificial Weathering}

Artificial weathering was conducted in a UV-chamber QUV (Q-Lab, Cleveland, OH, USA) on the basis of modified EN 927-6 [59] (Table 3). During the weekly cycle of irradiation and spraying, the samples were transferred to a conditioning chamber Discovery My DM340 (ACS, Massa Martana, Italy) and exposed to three-hour cycles of temperature changes from -25 to $80^{\circ} \mathrm{C}$ (with $25 \%$ relative air humidity). The temperature cycles lasted $6 \mathrm{~h}$ in total. The alternation of UV radiation, spray, and low temperature cycles was also used in a study by Van den Bulcke et al. [60]. This leads to a more accurate imitation of the exterior conditions in Europe, and to acceleration of artificial weathering tests. The total weathering time consisted of $1008 \mathrm{~h}$ ( 6 weeks) of UV cycling and $36 \mathrm{~h}$ of temperature cycling.

Table 3. One cycle of weathering in a UV-chamber according to modified EN 927-6 [59].

\begin{tabular}{cccc}
\hline \multicolumn{3}{c}{ Weathering in UV-Chamber: } \\
One Cycle $=\mathbf{1}$ Week (168 h)
\end{tabular}

Note: According to EN 927-6: 2006, the UV-chamber parameters in the 2nd step/A are as follows: Temperature $=60 \pm 3{ }^{\circ} \mathrm{C}$, UV Irradiance $=0.89 \mathrm{~W} \cdot \mathrm{m}^{-2}$ at $340 \mathrm{~nm}$.

The following parameters of the tested oak samples: colour, gloss and surface wettability were measured after $0,1,3$, and 6 weeks of artificial weathering and temperature cycling. 


\subsection{Colour Analyses}

The colour parameters (CIE 1986 [58]) of the tested samples were measured after 1, 3, and 6 weeks of weathering using Spectrophotometer CM-600d (Konica Minolta, Osaka, Japan). The device was set to an observation angle of $10^{\circ}, \mathrm{d} / 8$ geometry and D65 light source, and the SCI method was used. Six measurements per sample exposed to artificial weathering were carried out for each weathering time (Figure 1). Evaluations were done in CIE- $L^{*} a^{*} b^{*}$ colour space on the basis of $L^{*}, a^{*}$, and $b^{*}$ colour coordinates, where: $L^{*}$ is lightness from 0 (black) to 100 (white), $a^{*}$ is chromaticity coordinate + (red) or - (green), and $b^{*}$ is chromaticity coordinate + (yellow) or - (blue). The relative changes in colour $\left(\Delta L^{*}, \Delta a^{*}\right.$, and $\Delta b^{*}$ ) between the weathered and the initial state were determined. According to the Euclidean distance, the total colour difference $\Delta E^{*}$ (CIE 1986 [58]) was subsequently calculated using Equation (1):

$$
\Delta E *=\sqrt{\Delta L *^{2}+\Delta a *^{2}+\Delta b *^{2}}
$$

\subsection{Gloss Changes}

Gloss measurements were performed on the basis of EN ISO 2813 [61] using glossmeter MG268-F2 (KSJ, Quanzhou, China). Six measurements at a $60^{\circ}$ angle per sample after 1, 3, and 6 weeks of weathering were done to evaluate gloss changes (Figure 1).

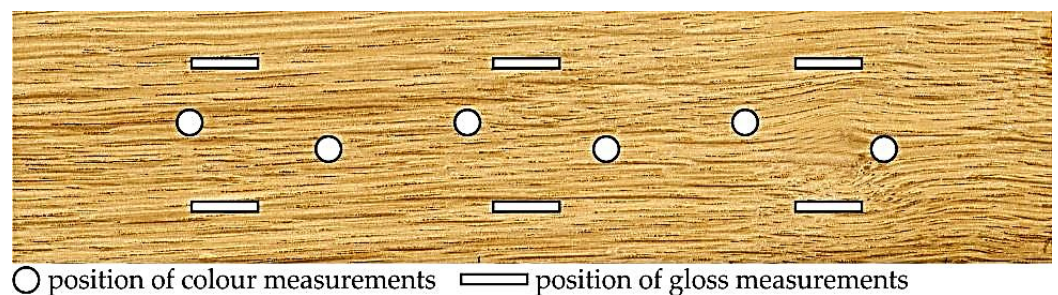

Figure 1. Scheme of colour and gloss measurements on the surfaces of tested oak wood samples.

\subsection{Surface Wettability}

The effect of artificial exposure on surface wettability was investigated. The water contact angle on tangential surfaces of oak wood samples was measured using a goniometer Krüss DSA 30E (Krüss, Hamburg, Germany). There are additional methods by which the water contact angle on wood surfaces [62] can be measured. The sessile drop method was used to compare the wettability of different surface treatments during artificial weathering. Ten measurements per sample were performed after 1,3, and 6 weeks of weathering with distilled water drops with a dosing volume of $5 \mu \mathrm{L}$. This was done in order to minimise the effects of the structural and chemical variations of the wood samples. As in other studies [63-65], the contact angle measurements were done at $5 \mathrm{~s}$ after the deposition of the water drop on the surface. The phenomena of spreading and absorption of drops on the wood surface was investigated using a variation of the artificial weathering time and the type of surface treatment. This method was used for the contact angle measurements of two hydrophobic coatings applied on 4 types of modified oak surfaces, and for the oil coating applied on the native oak surface (See Section 2.1).

\subsection{Microscopic Analysis}

Microscopic structural changes of coatings and wood surfaces were studied using confocal laser scanning microscope Lext Ols 4100 (Olympus, Tokyo, Japan) with 108-fold magnification.

\subsection{Statistical Evaluation}

Statistical analyses were performed in MS Excel and Statistica (StatSoft, Palo Alto, CA, USA) using mean values, standard deviations, and whisker plots with mean values and $95 \%$ two-sided confidence intervals. 


\section{Results and Discussion}

The results of the conducted experiments (Figures 2-7, Table 4) confirmed that the development of durable transparent surface protection for wood exposed to external conditions is complicated, and that the field of research in this area is still open [66]. This fact was emphasized even more through the use of oak as the underlying wood species. Due to its complicated morphological structure and large vessels [53], and the specific tannins content [67], the durability of exterior coatings applied to oak wood is relatively low [57]. Many commercial producers try to cope with this issue and do not recommend applying their coatings to oak wood, especially in transparent design; on the other hand, the high extractives content in oak protects its wood against bio-damage [54].

Table 4. Relative changes in the colour parameters $\Delta L^{*}, \Delta a^{*}, \Delta b^{*}$ (CIELab 1986 [58]) of the tested samples after 1, 3, and 6 weeks of artificial weathering. (Mean values from 12 measurements)

\begin{tabular}{|c|c|c|c|c|c|c|c|c|c|c|c|c|c|}
\hline \multirow{2}{*}{\multicolumn{2}{|c|}{$\begin{array}{c}\text { Coating } \\
\text { Modification }\end{array}$}} & \multicolumn{5}{|c|}{ A } & \multicolumn{5}{|c|}{ B } & \multirow{2}{*}{$\begin{array}{l}\mathrm{C} \\
-\end{array}$} & \multirow{2}{*}{$\begin{array}{c}\text { REF } \\
-\end{array}$} \\
\hline & & 1 & 2 & 3 & 4 & - & 1 & 2 & 3 & 4 & - & & \\
\hline Sig1 & & A1 & A2 & A3 & A4 & A & B1 & B2 & B3 & B4 & B & $C$ & REF \\
\hline \multirow{3}{*}{1 week } & $\Delta L^{*}$ & 10.8 & 10.2 & 13.9 & 2.5 & 3.7 & 2.3 & 14.0 & 14.0 & -0.6 & 2.2 & -3.5 & -1.9 \\
\hline & $\Delta a^{*}$ & -2.3 & -2.0 & -3.9 & 0.1 & -1.5 & 1.4 & -2.3 & -2.7 & 0.7 & 0.5 & 3.5 & 1.1 \\
\hline & $\Delta b^{*}$ & -7.0 & -3.2 & -10.0 & 0.9 & -5.3 & 1.5 & -4.9 & -9.2 & -1.7 & -1.9 & 4.9 & -0.2 \\
\hline \multirow{3}{*}{3 weeks } & $\Delta L^{*}$ & 19.7 & 16.1 & 18.8 & 8.1 & 9.4 & 12.5 & 20.5 & 19.6 & 9.0 & 8.8 & 1.7 & 11.1 \\
\hline & $\Delta a^{*}$ & -5.9 & -5.4 & -6.2 & -2.2 & -4.0 & -3.1 & -5.3 & -4.8 & -3.5 & -2.3 & -0.2 & -2.7 \\
\hline & $\Delta b^{*}$ & -14.8 & -9.8 & -13.7 & -4.8 & -9.5 & -9.4 & -9.1 & -12.6 & -8.8 & -7.4 & -2.4 & -8.0 \\
\hline \multirow{3}{*}{6 weeks } & $\Delta L^{*}$ & 23.5 & 23.2 & 25.2 & 10.8 & 15.5 & 17.7 & 25.4 & 24.3 & 11.2 & 14.7 & 15.2 & 14.4 \\
\hline & $\Delta a^{*}$ & -7.3 & -7.5 & -8.1 & -3.1 & -6.1 & -4.7 & -6.7 & -6.3 & -4.6 & -4.4 & -6.8 & -4.0 \\
\hline & $\Delta b^{*}$ & -15.5 & -12.7 & -16.3 & -4.2 & -13.0 & -11.3 & -9.4 & -13.7 & -7.6 & -9.9 & -12.2 & -7.9 \\
\hline
\end{tabular}

Note: For example, sign A1 means that the oak wood surface was modified by 2-(2-hydroxyfenyl)-benzotriazoles with HALS (1), and then a top layer of hydrophobic coating (A) was applied (See Table 1).

During wood exposure to UV radiation, depolymerization of lignins and extractives associated with a decrease in the $L^{*}$ value (darkening) and simultaneous increase of $a^{*}$ values (red shades) and $b^{*}$ (yellow shades) $[68,69]$ occured. However, if the depolymerized lignins and the extractives are washed out using water, the $L^{*}$ value increases (lightening) and values $a^{*}$ and $b^{*}$ decrease [70,71]. Leaching occurs when wood is exposed to weathering in the native state, or if the continuous protective coating layer is damaged [16]. In the case of natural weathering in the exterior, the wood subsequently turns gray (decrease of $L^{*}, a^{*}, b^{*}$ ) due to the deposition of dirt and the effects of moulds or wood-staining fungi $[20,72]$. These subsequent changes do not occur during artificial weathering in a UV-chamber with demineralized water and a pure indoor environment, and only an overall colour loss on the exposed wood surfaces takes place [70]. The colour changes after 6 weeks of artificial weathering in all of the tested samples, including untreated ones, were very significant (Figure 2, Table 4). Only the colour changes of samples treated with an oil-based coating (C) were significantly lower compared to untreated oak after 3 weeks of artificial weathering (Figure 2). As mentioned above, high colour changes indicate a degradation of the protective coating layer and leaching of extractives [29] and lignins decomposed using UV light [16]. This result therefore showed that this type of coating provides sufficient protection for oak wood in the initial phase of the weathering test, wherein it prevents the wood from leaching degraded extractives and lignin — see also the initial decrease of $L^{*}$ values (darkening) associated with the increase of $a^{*}$ values (reddening) and $b^{*}$ values (yellowing) after 1 week of weathering (Figure 2, Table 4). The positive effect of hydrophobic coatings $[15,18]$ preventing leaching and a decrease in total colour changes $\Delta E^{*}$ was only observed after 3 weeks of weathering in cases when treatments $\mathrm{A} 4$, B, and B4 were used (Figure 2). However, after 6 weeks of weathering, only the combination of hydrophobic coatings with the surface modification of oak wood No. 4-polymeric resin base with UV stabilizers and IPBC fungicide, detected lower total colour changes $\Delta E^{*}$ compared to untreated native oak wood. Adversely, in the case of other UV-stabilizing modifications in water solutions or dispersions (No. 1-3), only one 
(No. 3)-Benzotriazoles + HALS, in combination with the top layer (B), approached the total colour changes of native oak wood after 6 weeks of artificial weathering (Figure 2). In all of the other cases (No. 1-3), lightening (increase of $L^{*}$ value) and the decrease of $a^{*}$ and $b^{*}$ (alternation to green and blue shades-see Equation (1)) occurred during the weathering test (Table 4). The remaining treatments were characterized by a significant colour change compared to untreated oak wood (Figure 2), which was associated with a certain darkening after their application (see Table 2), and subsequent leaching by water associated with more significant changes in colour parameters $\left(L^{*}, a^{*}\right.$ and $\left.b^{*}\right)$. Based on the results, it can be concluded that the use of UV-stabilizers only increases the colour stability of underlying wood if their leaching in external conditions is further prevented by a high-quality coating film [66]. According to the experimental results, using only the hydrophobic layer does not provide protection for the wood for a long period of time. Confocal laser scanning microscopy (Figures 3 and 4) proved the formation of microcracks in a continuous layer of hydrophobic coatings during artificial weathering (see Photo 2, 3, 5 and 6 in Figure 3, versus Photo 8, 9, 11, and 12 in Figure 4).

These findings support the hypothesis that although the hydrophobic coating function is partially preserved (see contact angle measurements in Figure 6-values of hydrophobic coating B), and that it allows for the trickling of larger drops of water, the leachable UV-depolymerized extractives and lignins diffuse through splits and cracks into the water remaining on the surface during exposure. This is connected to significant colour changes in the underlying wood, and to leaching of UV stabilizing additives (No. 1-3) applied as a water solution or dispersions (only No. 4 was stabilized using synthetic resins-see Table 1). The colour changes to the exposed samples are also demonstrated in Figure 7.

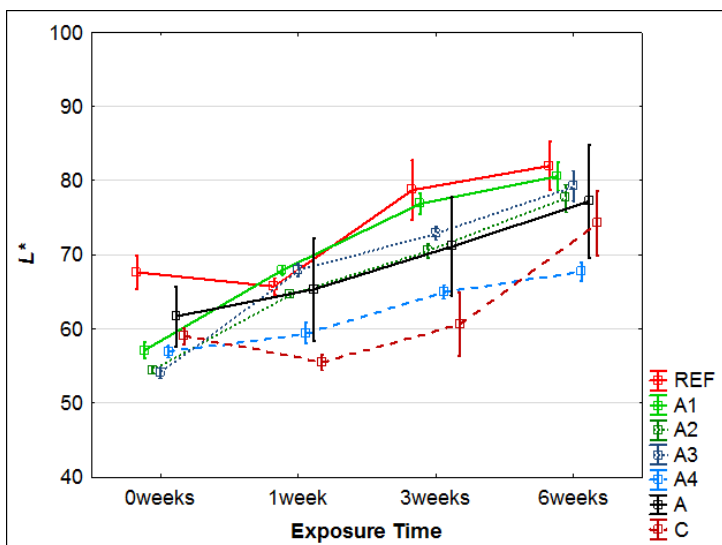

(a)

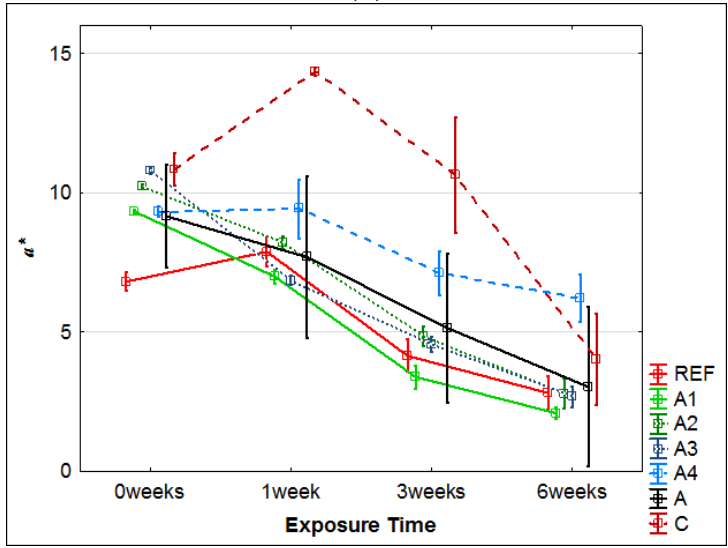

(c)

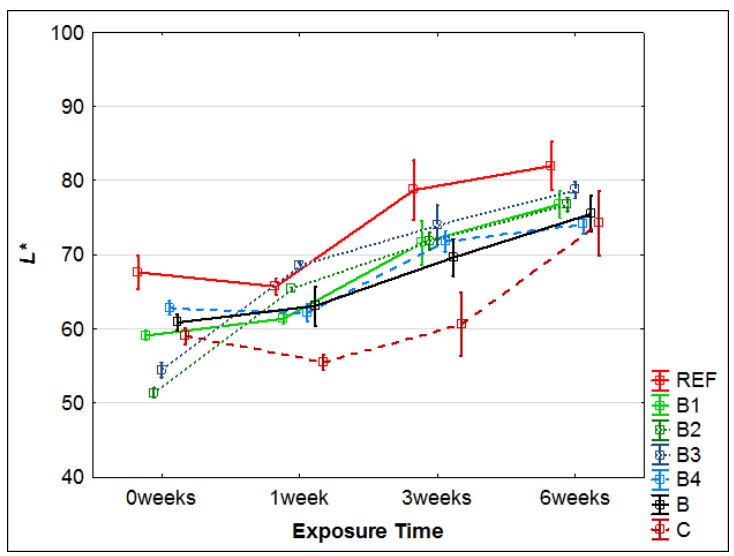

(b)

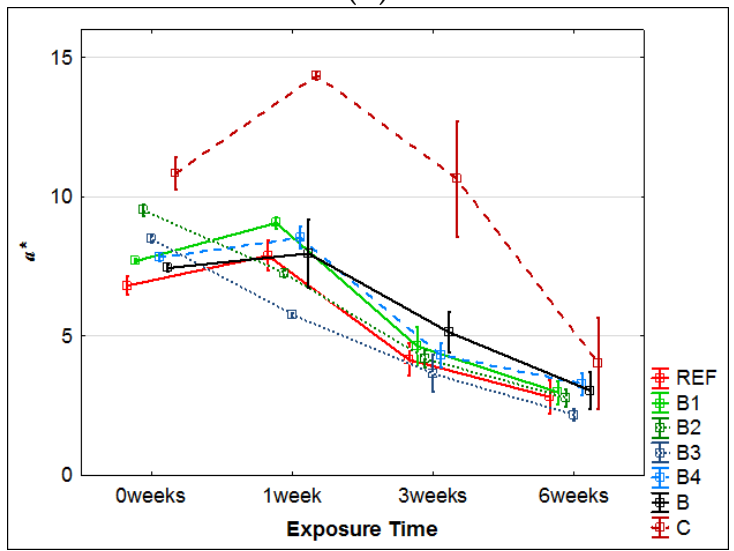

(d)

Figure 2. Cont. 


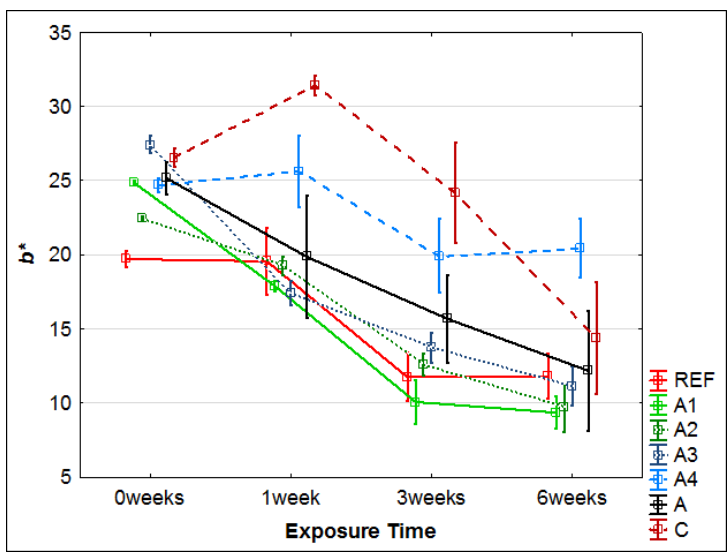

(e)

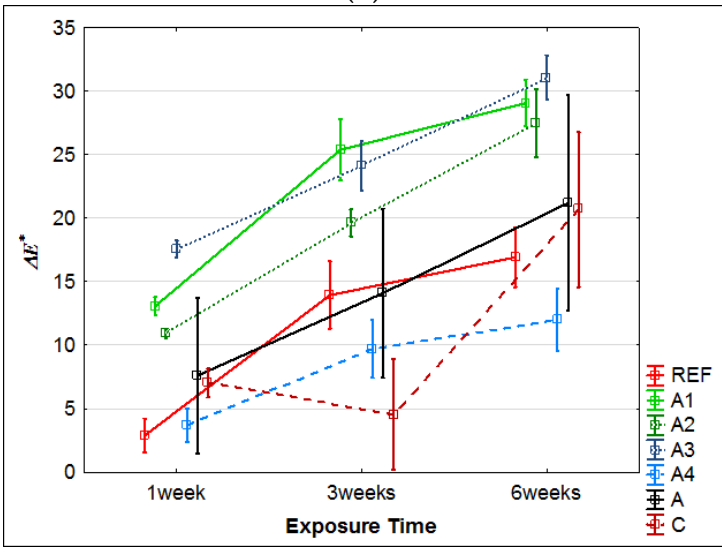

(g)

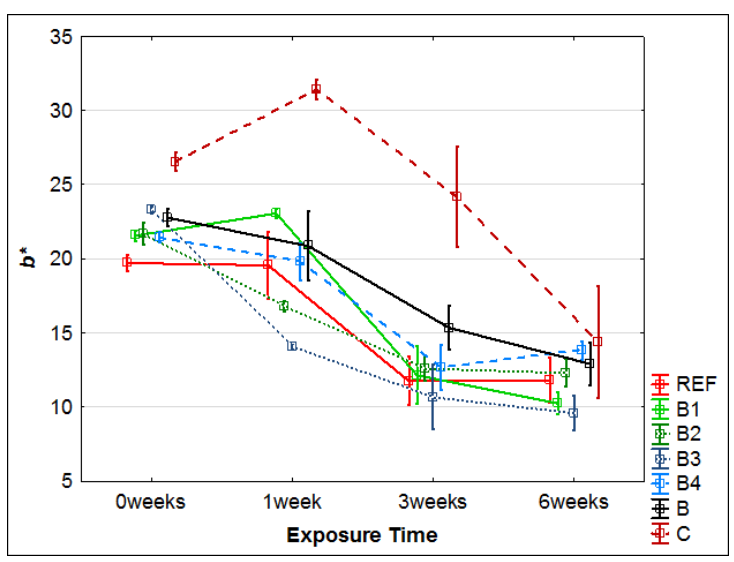

(f)

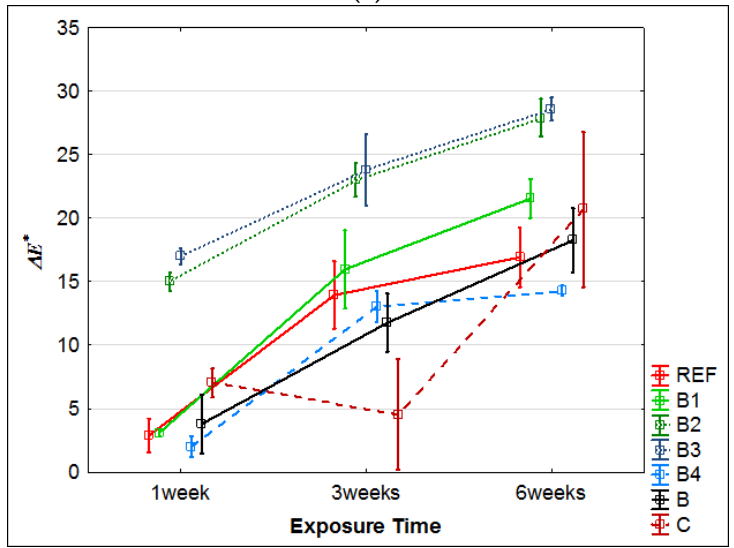

(h)

Figure 2. Colour changes to tested coatings during 6 weeks of artificial weathering. REF: native untreated oak wood; A: oak wood with the nano-based hydrophobic coating; B: oak wood with the hydrophobic coating with wax additives; 1, 2, 3, 4: the types of oak wood surface treatments; C: oil-based coating. (a) Increasing of $L^{*}$ values (lightness) of hydrophobic coating (A) with different surface treatments of oak wood (No. 1-4-see Tables 1 and 2); (b) Increasing of $L^{*}$ values (lightness) of hydrophobic coating (B) with different surface treatments of oak wood (No. 1-4); (c) Decreasing of $a^{*}$ values (red shades) of hydrophobic coating (A) with different surface treatments of oak wood (No. 1-4); (d) Decreasing of $a^{*}$ values (red shades) of hydrophobic coating (B) with different surface treatments of oak wood (No. 1-4); (e) Decreasing of $b^{*}$ values (yelow shades) of hydrophobic coating (A) with different surface treatments of oak wood (No. 1-4); (f) Decreasing of $b^{*}$ values (yelow shades) of hydrophobic coating (B) with different surface treatments of oak wood (No. 1-4); (g) Total colour changes $\Delta E^{*}$ of hydrophobic coating (A) with different surface treatments of oak wood (No. 1-4); (h) Total colour changes $\Delta E^{*}$ of hydrophobic coating (B) with different surface treatments of oak wood (No. 1-4). Comparison with untreated oak wood (REF_-similar trends) and oil-based coating (C-initial higher increasing of $a^{*}$ and $b^{*}$ values and their final decreasing) is shown. 

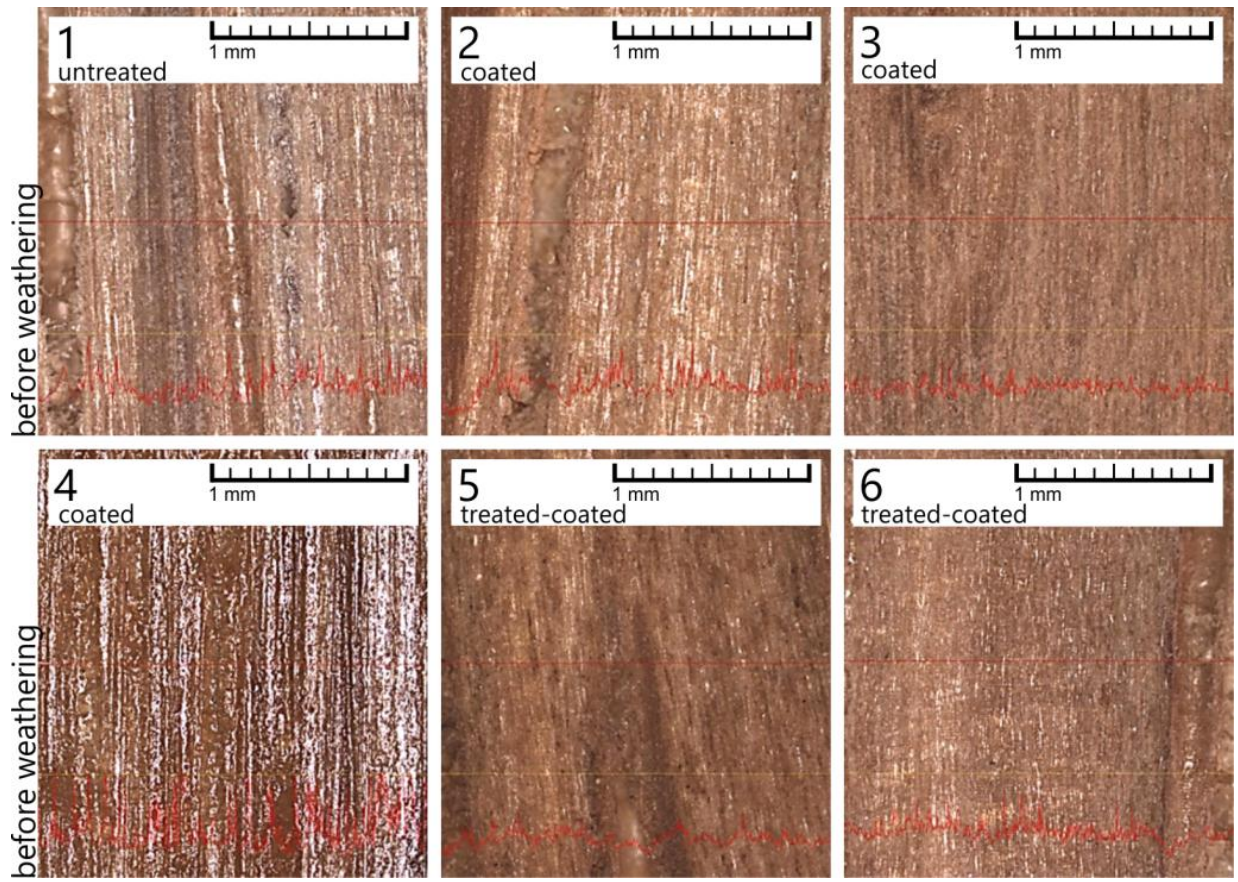

Figure 3. Samples before artificial weathering ( 0 weeks); reference untreated oak (1); oak treated with hydrophobic coating A (2); oak treated with hydrophobic coating B (3); oak treated with oil based coating C (4); oak with surface modification No. 3 and hydrophobic coating A (5); oak with surface modification No. 4 and hydrophobic coating B (6).

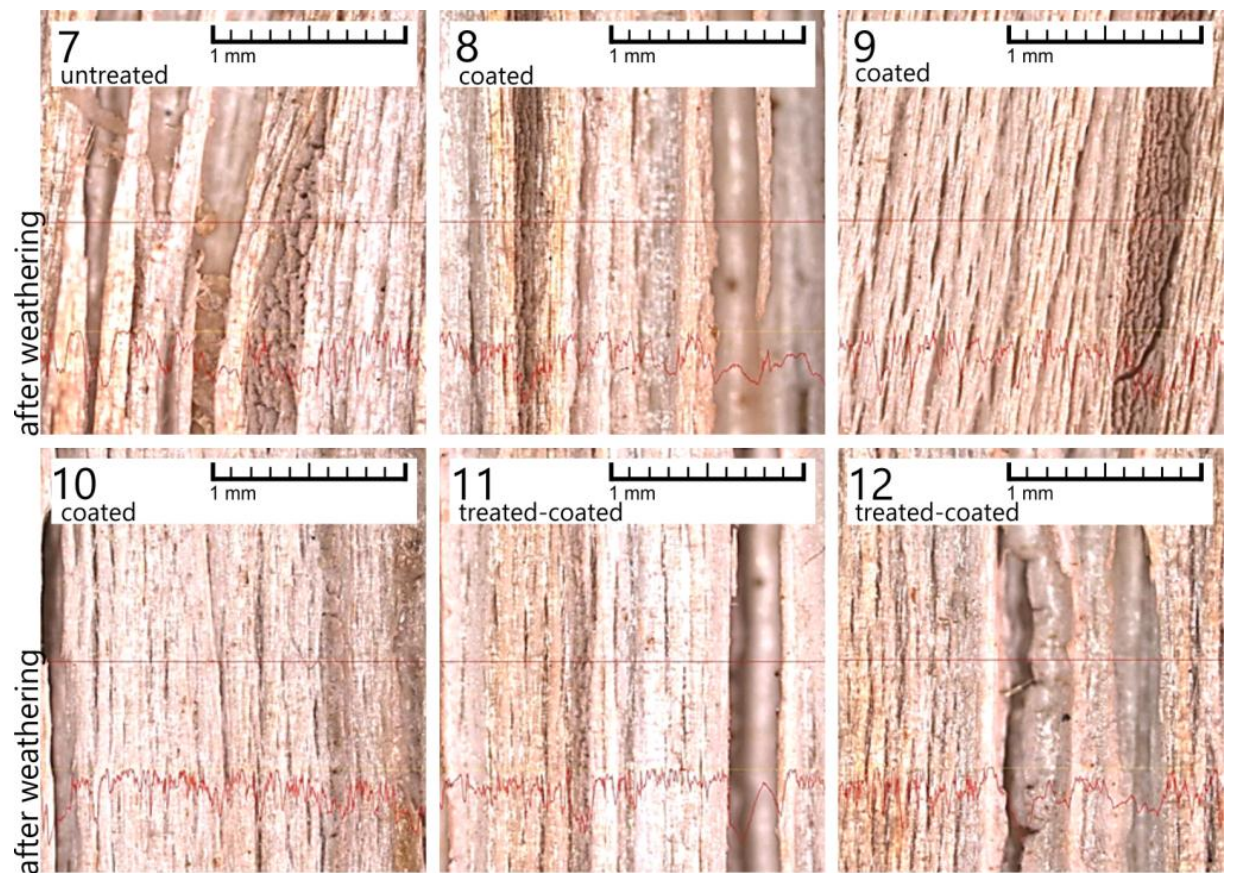

Figure 4. Samples after 6 weeks of artificial weathering (6 weeks); reference untreated oak (7); oak treated with hydrophobic coating A (8); oak treated with hydrophobic coating B (9); oak treated with oil based coating C (10); oak with surface modification No. 3 and hydrophobic coating A (11); oak with surface modification No. 4 and hydrophobic coating B (12). Visible degradation of tested coatings, opening of oak vessels, and creation of micro-cracks and cracks on all tested surfaces. 
Using only hydrophobic coatings does not cause a significant increase in the gloss of the underlying wood (Figure 5). Unlike the oil coatings (C), hydrophobic coatings do not change the oak's natural appearance (Figure 5). The gloss of the treated and untreated oak wood did not change significantly during the exposure (Figure 5). Only in the case of oil-based coating (C) was the gloss change an indicator of its initiating degradation after 3 weeks of weathering (Figure 5). The degradation process was fully manifested after 6 weeks of weathering (Photo 10) via a change in gloss, as well as a significant change in colour (Figure 2) and contact angle (Figure 6). From this point of view, the gloss change is more sensitive to the coating degradation than to total colour difference. The effect of gloss change during degradation is also mentioned in the study by Ghosh et al. [73].

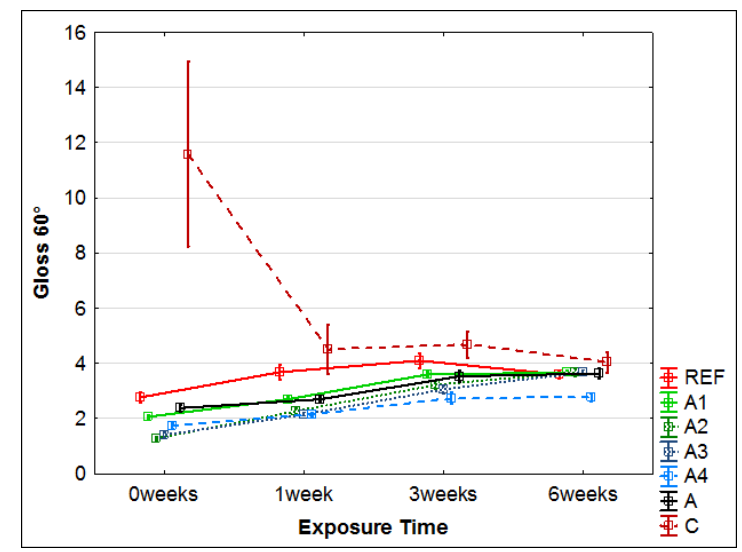

(a)

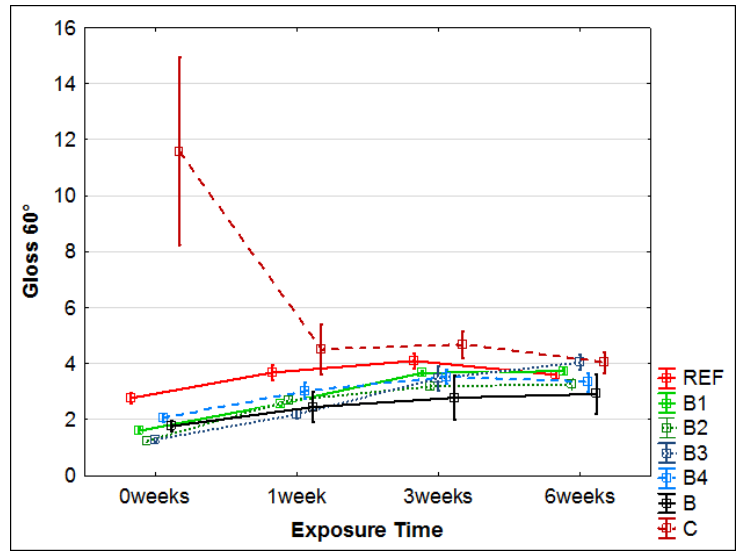

(b)

Figure 5. Gloss changes of tested coatings during 6 weeks of artificial weathering. REF: native untreated oak wood; A: oak wood with the nano-based hydrophobic coating; B: oak wood with the hydrophobic coating with wax additives; 1 , 2, 3, 4: the types of oak wood surface treatments; C: oil-based coating. (a) Relativelly small gloss changes of hydrophobic coating (A) with different surface treatments of oak wood (No. 1-4-see Tables 1 and 2); (b) Relativelly small gloss changes of hydrophobic coating (B) with different surface treatments of oak wood (No. 1-4). Comparison with untreated oak wood (REF-similar trends) and oil-based coating (C-high decrease of gloss after 1 week of accelerated weathering) is shown.

The applied coatings were also analyzed from the point of the surface wetting of treated wood, which is directly related to adhesion or penetration [74,75]. For all surface treatments (modifications 1-4 and untreated oak), penetration of hydrophobic coatings (A) and (B) was already observed at 1 and $3 \mathrm{~s}$, respectively. Oil coating $(\mathrm{C})$ reached a contact angle value of $29.6^{\circ}\left(\mathrm{SD}=4.9^{\circ}\right)$. This indicates that in no case was there a problem with the application of the coating due to worse surface wetting of modified wood.

The wetting contact angle (Figure 6) provides an overview of the functionality of hydrophobic layers during weathering. Based on the results, there is a significant loss of functionality due to weathering. Before weathering, the contact angle of the wood surfaces was close to $140^{\circ}$, meaning almost superhydrophobic (contact angle $=150^{\circ}$ ). The results were different for hydrophobic coatings (A) and (B). For coating (A), the decrease in the contact angle value was more significant, especially after 3 weeks of weathering, and after 6 weeks, the surface was hydrophobic only in combination with surface modification No. 2 (benzotriazole and HALS in the mixture with ZnO nanoparticles). This is likely due to the fact that water-based coating (A) did not contain a polymeric base (Table 1) that would stabilize it during water and UV exposure. For coating (B), this polymer base (Table 1) provided coating stability for approximately 3 weeks of weathering (Figure 6), and a significant decrease due to the depolymerization and leaching of degraded products after 6 weeks of weathering was subsequently observed. Overall, it is interesting to note that the use of smaller $\mathrm{TiO}_{2}$ nanoparticles (Table 1 ) led to 
faster degradation (Figures 2 and 6). As mentioned in the study by Moya et al. [76], it is likely that the smaller particles more easily penetrate into the applied coating and interfere with its integral polymer chain structure.

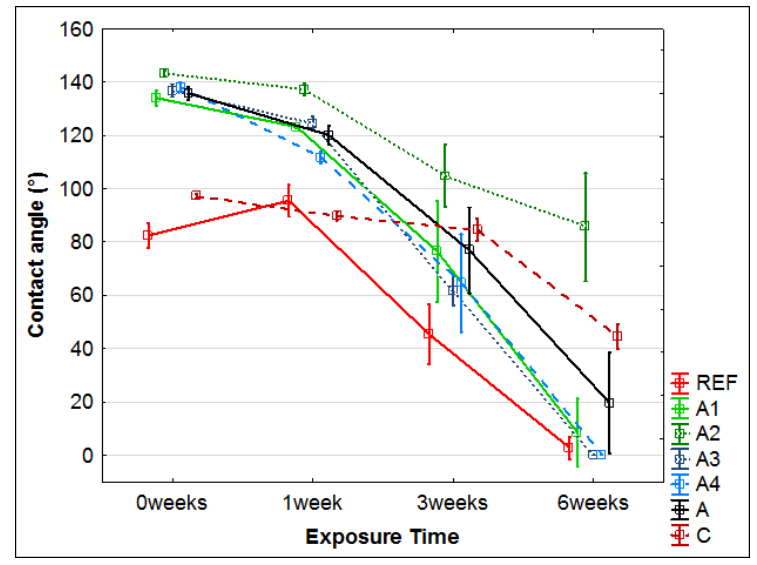

(a)

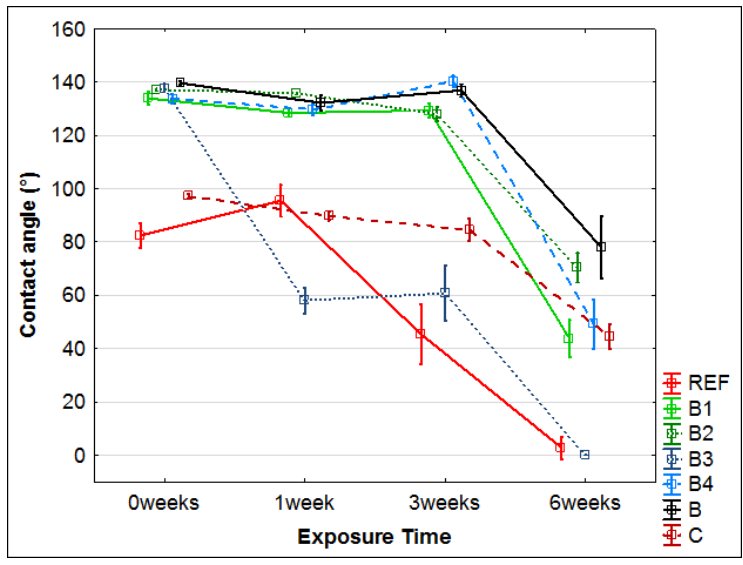

(b)

Figure 6. Changes in the contact angle of tested coatings during 6 weeks of artificial weathering. REF: native untreated oak wood; A: oak wood with the nano-based hydrophobic coating; B: oak wood with the hydrophobic coating with wax additives; 1, 2, 3, 4: the types of oak wood surface treatments; C: oil-based coating. (a) Decreasing of hydrophobicity of hydrophobic coating (A) with different surface treatments of oak wood (No. 1-4-see Tables 1 and 2); (b) Decreasing of hydrophobicity of hydrophobic coating (B) with different surface treatments of oak wood (No. 1-4). Comparison with untreated oak wood (REF) and oil-based coating (C) is shown.

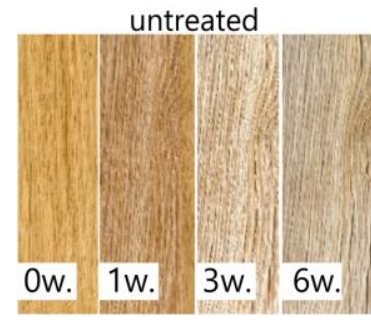

(a)

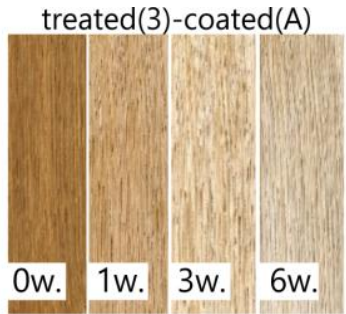

(b)

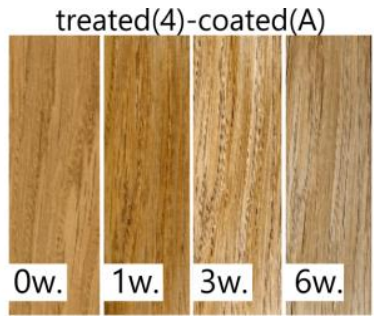

(c)

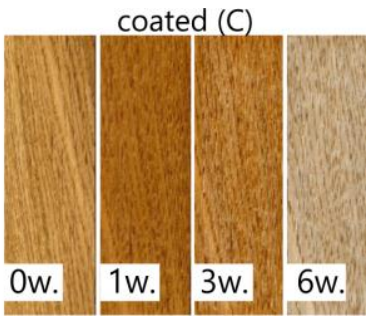

(d)

Figure 7. Photo demonstrating colour changes of selected tested samples after $0,1,3$, and 6 weeks (w.) of accelerated weathering. (a) native untreated oak wood; (b) treated (3)-coated (A); (c) treated (4)-coated (A); (d) coated (C). A: oak wood with the nano-based hydrophobic coating; 3, 4: the types of oak wood surface treatments; C: oil-based coating-see Tables 1 and 2. The similar trends of discolouration of hydrophobic coatings (B) and (A) were observed.

Based on the results, it can be concluded that the hydrophobic layers and the oil coating significantly increase the hydrophobicity of natural wood surfaces [14,77]. However, the increase in hydrophobicity after coating application [15,50,52] does not necessarily indicate long-term functionality during exposure to weathering (Figures 6 and 7). In general, the use of hydrophobic layers can only be recommended for sheltered wood (i.e., without leaching of extractives by water), which can lead to easier maintenance and cleaning during use. In the event of absence of overhangs and without ground contact (Class 3 by EN 335 [1]), this may lead to partial prolonging of the service life of less durable wood species [54] by reducing the occurrence of wood-destroying fungi due to decreased water uptake. However, this effect is only temporary. Adversely, a significant change in the wood colour can be expected, as the hydrophobic coatings do not prevent the leaching of extractives and degraded lignin of the underlying wood over the long-term. The experimental works $[23,26,36,78]$ also mentioned the 
important aspect of the influence of individual underlying wood species on the service life of surface treatment on its exterior. Since the degradation of the protective layer of hydrophobic coatings (A) and (B) occurred due to weathering, their significantly longer service life on an exterior with rain effects (Class 3 by EN 335 [1]) cannot be assumed - not even in the case of the application of other types of underlying wood. When exterior oil-based coating $(C)$ is applied, a longer service life can be expected in the case of softwoods [79] that have a morphological structure that is more simple than hardwoods with wide open vessels [57]. However, each underlying wood can affect the service life of the coating individually through the specific content of the extractives [27], and it is therefore necessary to confirm these assumptions by testing and comparing the evaluated characteristics $[20,23,25]$.

\section{Conclusions}

The potential use of two selected hydrophobic coatings protecting oak wood exposed to weathering on its exterior is discussed in this study. The underlying wood was stabilized using UV stabilizers, $\mathrm{HALS}$, and $\mathrm{ZnO}$ and $\mathrm{TiO}_{2}$ nanoparticles, or a mixture thereof, and an artificial weathering test was carried out. The results showed relatively rapid degradation of the tested hydrophobic coatings by UV radiation, water, and temperature changes and subsequent formation of micro-cracks on the surface of the treated wood. Even though the hydrophobic coatings partially preserve the hydrophobic characteristics during weathering, they do not prevent leaching of depolymerized lignins and extractives from wood (not even when UV stabilizers are used in the penetrating base layer). This process results in significant colour changes. A hydrophobic coating based on synthetic resins and waxes demonstrated better durability against weathering and higher hydrophobicity after 6 weeks of weathering compared to coating based on zirconium nanoparticles in butanol. The oil-based coating that was used as a reference proved to be more durable against degradation caused by artificial weathering, but after 6 weeks of the weathering test, its complete degradation connected with significant changes in the structure of the underlying wood was observed. The results confirmed the possibility to achieve a hydrophobic effect of wood through the application of surface modification; however, long-term stability is also necessary. Tested hydrophobic coatings can be recommended for application in the exposure situations without direct rainwater contact, i.e., conditions which can be provided by an appropriate design solution. For outdoor exposures with rainwater contact, film-forming, multilayer coatings should be used in order to preserve the native appearance of wood for a longer period of time.

Acknowledgments: The authors are very grateful for the financial support of the University Internal Grant Agency of the Czech University of Life Sciences, Prague, Project CIGA No. 20174304 “Design of coating system and modification of artificial weathering test procedures applied on selected wood species".

Author Contributions: Miloš Pánek conceived, designed the experiments, analyzed the data and wrote the paper; Eliška Oberhofnerová performed the experiments and co-wrote paper; Aleš Zeidler performed the experiments and co-wrote the paper; Přemysl Šedivka performed the experiments and co-wrote the paper.

Conflicts of Interest: The authors declare no conflict of interest.

\section{References}

1. EN 335:2013 Durability of Wood and Wood-Based Products-Use Classes: Definitions, Application to Solid Wood and Wood-Based Products; European Committee for Standardization: Brussels, Belgium, 2013.

2. Weiland, J.J.; Guyonnet, R. Study of chemical modifications and fungi degradation of thermally modified wood using DRIFT spectroscopy. Holz Roh Werkst. 2003, 61, 216-220. [CrossRef]

3. Reinprecht, L. Wood Deterioration, Protection and Maintenance, 1st ed.; Wiley-Blackwell: Hoboken, NJ, USA, 2016; p. 376.

4. Owen, J.A.; Owen, N.L.; Feist, W.C. Scanning electron microscope and infrared studies of weathering in Southern pine. J. Mol. Struct. 1993, 300, 105-114. [CrossRef] 
5. Kiguchi, M.; Evans, P.D.; Ekstedt, J.; Williams, R.S.; Kataoka, Y. Improvement of the durability of clear coatings by grafting of UV-absorbers on to wood. Surf. Coat. Int. Part B Coat. Trans. 2001, 84, 263-270. [CrossRef]

6. Williams, R.S. Effect of grafted UV stabilizers on wood surface erosion and clear coating performance. J. Appl. Polym. Sci. 1983, 28, 2093-2103. [CrossRef]

7. Raczkowski, J. Seasonal effects on the atmospheric corrosion of spruce micro-sections. Holz Roh Werkst. 1980, 38, 231-234. [CrossRef]

8. Mai, C.; Militz, H. Modification of wood with silicon compounds. Treatment systems based on organic silicon compounds-A review. Wood Sci. Technol. 2004, 37, 453-461. [CrossRef]

9. Burgert, I.; Cabane, E.; Zollfrank, C.; Berglund, L. Bio-inspired functional wood-based materials-Hybrids and replicates. Int. Mater. Rev. 2015, 60, 431-450. [CrossRef]

10. Hill, C.A.S. Wood Modification-Chemical, Thermal and Other Processes; John Wiley and Sons Ltd.: Chichester, UK, 2006; p. 239.

11. Larsson-Brelid, P.; Simonson, R.; Bergman, Ö.; Nilsson, T. Resistance of acetylated wood to biological degradation. Holz Roh Werkst. 2000, 58, 331-337. [CrossRef]

12. Liu, F.; Wang, S.; Zhang, M.; Ma, M.; Wang, C.; Li, J. Improvement of mechanical robustness of the superhydrophobic wood surface by coating $\mathrm{PVA} / \mathrm{SiO}_{2}$ composite polymer. Appl. Surf. Sci. 2013, 280, 686-692. [CrossRef]

13. Ikei, H.; Song, C.; Miyazaki, Y. Physiological effects of wood on humans: A review. J. Wood Sci. 2017, 63, 1-23. [CrossRef]

14. Yao, L.; He, J. Recent progress in antireflection and self-cleaning technology-From surface engineering to functional surfaces. Prog. Mater. Sci. 2014, 61, 94-143. [CrossRef]

15. Samyn, P.; Stanssens, D.; Paredes, A.; Becker, G. Performance of organic nanoparticle coatings for hydrophobization of hardwood surfaces. J. Coat. Technol. Res. 2014, 11, 461-471. [CrossRef]

16. Sudiyani, Y. Chemical characteristics of surfaces of hardwood and softwood deteriorated by weathering. J. Wood Sci. 1999, 45, 348-353. [CrossRef]

17. Sun, Q.; Lu, Y.; Liu, Y. Growth of hydrophobic $\mathrm{TiO}_{2}$ on wood surface using a hydrothermal method. J. Mater. Sci. 2011, 46, 7706-7712. [CrossRef]

18. Wang, X.; Chai, Y.; Liu, J. Formation of highly hydrophobic wood surfaces using silica nanoparticles modified with long-chain alkylsilane. Holzforschung 2013, 394, 97-112. [CrossRef]

19. Petrič, M.; Knehtl, B.; Krause, A.; Militz, H.; Pavlič, M.; Pétrissans, M.; Rapp, A.; Tomažič, M.; Welzbacher, C.; Gérardin, P. Wettability of waterborne coatings on chemically and thermally modified pine wood. J. Coat. Technol. Res. 2007, 4, 203-206. [CrossRef]

20. Pánek, M.; Reinprecht, L. Effect of the number of UV-protective coats on the color stability and surface defects of painted black locust and Norway spruce woods subjected to natural weathering. BioResources 2016, 11, 4663-4676. [CrossRef]

21. Blanchard, V.; Blanchet, P. Color Stability for wood products during use: Effects of inorganic nanoparticles. BioResources 2011, 6, 1219-1229.

22. Allen, S.N.; Edge, M.; Ortega, A.; Liauw, C.M.; Stratton, J.; McIntyre, R.B. Behaviour of nanoparticle (ultrafine) titanium dioxide pigments and stabilisers on the photooxidative stability of water-based acrylic and isocyanate based acrylic coatings. Polym. Degrad. Stab. 2002, 78, 467-478. [CrossRef]

23. De Windt, I.; van den Bulcke, J.; Wuijtens, I.; Coppens, H.; van Acker, J. Outdoor weathering performance parameters of exterior wood coating systems on tropical hardwood substrates. Eur. J. Wood Wood Prod. 2014, 72, 261-272. [CrossRef]

24. Grüll, G.; Tscherne, F.; Spitaler, I.; Forsthuber, B. Comparison of wood coating durability in natural weathering and artificial weathering using fluorescent UV-lamps and water. Eur. J. Wood Wood Prod. 2014, 72, 367-376. [CrossRef]

25. De Meier, M. Review on the durability of exterior wood coatings with reduced VOC-content. Prog. Org. Coat. 2001, 43, 217-225. [CrossRef]

26. Ozgenc, O.; Hiziroglu, S.; Yildiz, U.C. Weathering properties of wood species treated with different coating applications. BioResources 2012, 7, 4875-4888. [CrossRef]

27. Grüll, G.; Forsthuber, B.; Ecker, M. Sensitivity of waterborne coatings materials to high acidity and high content of arabinobalactan in larch heartwood. Prog. Org. Coat. 2016, 101, 367-378. [CrossRef] 
28. Hon, D.N.S.; Chang, S.T. Surface degradation of wood by ultraviolet light. J. Polym. Sci. Polym. Chem. 1984, 22, 2227-2241. [CrossRef]

29. Pandey, K.K. A note on the influence of extractives on the photo-discoloration and photo-degradation of wood. Polym. Degrad. Stab. 2005, 87, 375-379. [CrossRef]

30. Pastore, T.C.M.; Santos, K.O.; Rubim, J.C. A spectrocolorimetric study on the effect of ultraviolet irradiation of four tropical hardwoods. Bioresour. Technol. 2004, 93, 37-42. [CrossRef] [PubMed]

31. Genco, G.; Lo Monaco, A.; Pelosi, C.; Picchio, R.; Santamaria, U. A study of colour change due to accelerated sunlight exposure in consolidated wood samples. Wood Res. 2011, 56, 511-524.

32. Forsthuber, B.; Schaller, C.; Grüll, G. Evaluation of the photo stabilizing efficiency of clear coatings comprising organic UV absorbers and mineral UV screeners on wood surfaces. Wood Sci. Technol. 2013, 47, 281-297. [CrossRef]

33. Weichelt, F.; Emmler, R.; Flyunt, R.; Beyer, E.; Buchmeiser, M.R.; Beyer, M. ZnO-based UV nanocomposites for wood coatings in outdoor applications. Macromol. Mater. Eng. 2010, 295, 130-136. [CrossRef]

34. Cayton, R.H.; Murray, P.G.; Nelson, D.; Ostrowski, R. Improved weatherability of outdoor wood stains using nanotechnology. J. Coat. Technol. 2010, 7, 38-42.

35. Poubel, D.D.; Garcia, R.A.; Lelis, R.C.C.; Riedl, B. Effect of ZnO nanoparticles on UV resistance of the heat-treated pine wood. Sci. For. 2017, 113, 49-62. [CrossRef]

36. Robinson, S.C.; Tudor, D.; Mansourian, Y.; Cooper, P.A. The effects of several commercial wood coatings on the deterioration of biological pigments in wood exposed to UV light. Wood Sci. Technol. 2013, 47, 457-466. [CrossRef]

37. Schaller, C.; Rogez, D. New approaches in wood coating stabilization. J. Coat. Technol. Res. 2007, 4, 401-409. [CrossRef]

38. George, B.; Suttie, E.; Merlin, A.; Deglise, X. Photodegradation and photostabilisation of wood-The state of the art. Polym. Degrad. Stab. 2005, 88, 268-274. [CrossRef]

39. Kurumada, T.; Ohsawa, H.; Yamazaki, T. Synergism of hindered amine light stabilizers and UV-absorbers. Polym. Degrad. Stab. 1987, 19, 262-272. [CrossRef]

40. Evans, P.D.; Thay, P.D.; Schmalzl, K.J. Degradation of wood surfaces during natural weathering. Effects on lignin and cellulose and on the adhesion of acrylic latex primers. Wood Sci. Technol. 1996, 30, 411-422.

41. Gobakenn, L.R.; Westin, M. Surface moulds growth on five modified wood substrates coated with three different coating systems when exposed outdoors. Int. Biodeterior. Biodegrad. 2008, 62, 397-402. [CrossRef]

42. Van Acker, J.; Stevens, M.; Carey, J.; Siera-Alvarez, R.; Militz, H.; Le Bayon, I.; Kleist, G.; Peek, R.D. Biological durability of wood in relation to end-use-Part 1. Towards a European standard for laboratory testing of the biological durability of wood. Holz Roh Werkst. 2003, 61, 125-132. [CrossRef]

43. Dubey, M.K.; Pang, S.; Walker, J. Changes in chemistry, color, dimensional stability and fungal resistance of Pinus radiata D. Don wood with oil heat-treatment. Holzforschung 2011, 65, 49-57. [CrossRef]

44. Hukka, A.; Viitanen, H.A. A mathematical model of mould growth on wooden material. Wood Sci. Technol. 1999, 33, 475-485. [CrossRef]

45. Sahin, H.T.; Mantanis, G.I. Colour changes in wood surfaces modified by a nanoparticulate based treatment. Wood Res. 2011, 56, 525-532.

46. Grüll, G.; Truskaller, M.; Podgorski, L.; Bollmus, S.; Tscherne, F. Maintenance procedures and definition of limit states for exterior wood coatings. Eur. J. Wood Wood Prod. 2011, 69, 443-450. [CrossRef]

47. Rowell, R.; Bongers, F. Coating Acetylated Wood. Coatings 2015, 5, 792-801. [CrossRef]

48. Žlahtič, M.; Humar, M. Influence of artificial and natural weathering on the hydrophobicity and surface properties of wood. BioResources 2016, 11, 4964-4989. [CrossRef]

49. Ayadi, N.; Lejeune, F.; Charrier, F.; Charrier, B.; Merlin, A. Color stability of heat-treated wood during artificial weathering. Holz Roh Werkst. 2003, 61, 221-226. [CrossRef]

50. Wang, C.; Piao, C.; Lucas, C. Synthesis and characterization of superhydrophobic wood surfaces. J. Appl. Polym. Sci. 2011, 119, 1667-1672. [CrossRef]

51. Sébe, G.; Brook, M.A. Hydrophobization of wood surfaces: Covalent grafting of silicone polymers. Wood Sci. Technol. 2001, 35, 269-282. [CrossRef]

52. Šprdlík, V.; Kotradyová, V.; Tiňo, R. Superhydrophobic coating of European oak (Quercus robur), European larch (Larix decidua), and Scots pine (Pinus sylvestris) wood surfaces. BioResources 2017, 12, 3289-3302. [CrossRef] 
53. Wagenführ, R. Dřevo-Obrazový Lexikon; GRADA Publishing: Praha, Czech Republic, 2002; p. 348, ISBN 80-247-0346-7.

54. EN 350:2016 Durability of Wood and Wood-Based Products-Testing and Classification of the Durability to Biological Agents of Wood and Wood-Based Materials; European Committee for Standardization: Brussels, Belgium, 2016.

55. EN 460:1994 Durability of Wood and Wood-Based Products-Natural Durability of Solid Wood-Guide to the Durability Requirements for Wood to Be Used in Hazard Classes; European Committee for Standardization: Brussels, Belgium, 1994.

56. Oberhoffnerová, E.; Pánek, M.; Cimarras, A.G. The effect of natural weathering on untreated wood surface. Maderas Cienc. Tecnol. 2017, 19, 173-184. [CrossRef]

57. Sivrikaya, H.; Hafizoglu, H.; Yasav, A.; Aydemir, D. Natural weathering of oak (Quercus petrae) and chestnut (Castanea sativa) coated with various finishes. Color Res. Appl. 2011, 36, 72-78. [CrossRef]

58. Colorimetry, 2nd ed.; Commission Internationale de l'Eclairage: Vienna, Austria, 1986; p. 74.

59. EN 927-6:2006 Paints and Varnishes. Coating Materials and Coating Systems for Exterior Wood-Part 6: Exposure of Wood Coatings to Artificial Weathering Using Fluorescent UV Lamps and Water; European Committee for Standardization: Brussels, Belgium, 2006.

60. Van den Bulcke, J.; van Acker, J.; Stevens, M. Experimental and theorethical behavior of exterior wood coatings subjected to artificial weathering. J. Coat. Technol. Res. 2008, 5, 221-231. [CrossRef]

61. EN ISO 2813:2014 Paints and Varnishes-Determination of Gloss Value at 20 Degrees, 60 Degrees and 85 Degrees; European Committee for Standardization: Brussels, Belgium, 2014.

62. Kúdela, J. Wetting of wood surface by a liquids of a different polarity. Wood Res. 2014, 59, 11-24.

63. Wålinder, M.; Johansson, I. Measurement of wood wettability by the Willhelmy method. Part 1. Contamination of probe liquids by extractives. Holzforschung 2001, 55, 21-32. [CrossRef]

64. Bastani, A.; Adamopoulos, S.; Militz, H. Water uptake and wetting behaviour of furfurylated, $N$-methylol melamine modified and heat-treated wood. Eur. J. Wood Wood Prod. 2015, 73, 627-634. [CrossRef]

65. Gonzalez de Cademartori, P.H.; Missio, A.L.; Dufau Mattos, B.; Gatto, D.A. Natural weathering performance of three fast-growing Eucalypt woods. Maderas Cienc. Tecnol. 2015, 17, 799-808. [CrossRef]

66. Evans, P.D.; Haase, J.G.; Shakri, A.; Seman, B.M.; Kiguchi, M. The search for durable exterior clear coatings for wood. Coatings 2015, 5, 830-864. [CrossRef]

67. Krutul, D.; Radomski, A.; Zawadzki, J.; Zielenkiewicz, T.; Antczak, A. Comparison of the chemical composition of the fossil and recent oak wood. Wood Res. 2010, 55, 113-120.

68. Srinivas, K.; Pandey, K.K. Photodegradation of thermally modified wood. J. Photochem. Photobiol. B Biol. 2012, 117, 140-145. [CrossRef] [PubMed]

69. Calienno, L.; Pelosi, C.; Picchio, R.; Agresti, G.; Santamaria, U.; Balletti, F.; Lo Monaco, A. Light induced colour changes and chemical modification of treated and untreated chestnut wood surface. Stud. Conserv. 2015, 60, 131-139. [CrossRef]

70. Rüther, P.; Jelle, B.P. Color changes of wood and wood-based materials due to natural and artificial weathering. Wood Mater. Sci. Eng. 2013, 8, 13-25. [CrossRef]

71. Schnabel, T.; Zimmer, B.; Petutschnigg, A.J. On the modelling of colour changes of wood surfaces. Eur. J. Wood Wood Prod. 2009, 67, 141-149. [CrossRef]

72. Gaylarde, C.C.; Morton, L.H.G.; Loh, K.; Shirakawa, M.A. Biodeterioration of extrenal architectural paint films-A review. Int. Biodeterior. Biodegrad. 2011, 65, 1189-1198. [CrossRef]

73. Ghosh, M.; Gupta, S.; Kumar, V.S.K. Studies on the loss of gloss of shellac and polyurethane finishes exposed to UV. Maderas Cienc. Tecnol. 2015, 17, 39-44. [CrossRef]

74. Scheikl, M.; Dunky, M. Measurement of dynamic and static contact angels on wood for the determination of its surface tension and the penetration of liquids into the wood surface. Holzforschung 1998, 52, 89-94. [CrossRef]

75. Liptákova, E.; Kudela, J.; Sarvaš, J. Study of the system wood-Coating material. Part 1. Wood-Liquid coating material. Holzforschung 2000, 54, 189-196. [CrossRef]

76. Moya, R.; Rodríguez-Zúñiga, A.; Vega-Baudrit, J.; Puente-Urbina, A. Effects of adding $\mathrm{TiO}_{2}$ nanoparticles to a water-based varnish for wood applied to nine tropical woods of Costa Rica exposed to natural and accelerated weathering. J. Coat. Technol. Res. 2016, 14, 141-152. [CrossRef]

77. Mahendran, A.R.; Wuzella, G.; Aust, N.; Kandelbauer, A.; Müller, U. Photocrosslinkable modified vegetable oil-based resin for wood surface coating application. Prog. Org. Coat. 2012, 74, 697-704. [CrossRef] 
78. Gobakken, L.R.; Lebow, P.K. Modelling mould growth on coated modified and unmodified wood substrates exposed outdoors. Wood Sci. Technol. 2010, 44, 315-333. [CrossRef]

79. Pánek, M.; Reinprecht, L. Colour stability and surface defects of naturally aged wood treated with transparent paints for exterior constructions. Wood Res. 2014, 59, 421-430.

(c) 2017 by the authors. Licensee MDPI, Basel, Switzerland. This article is an open access article distributed under the terms and conditions of the Creative Commons Attribution (CC BY) license (http:// creativecommons.org/licenses/by/4.0/). 